\title{
ТОМ \\ How science, technology and innovation can be placed in broader visions - Public opinions from inclusive public engagement activities
}

\author{
Kei Kano, Mitsuru Kudo, Go Yoshizawa, Eri Mizumachi, Makiko Suga, \\ Naonori Akiya, Kuniyoshi Ebina, Takayuki Goto, Masayuki Itoh, \\ Ayami Joh, Haruhiko Maenami, Toshifumi Minamoto, Mikihiko Mori, \\ Yoshitaka Morimura, Tamaki Motoki, Akie Nakayama and \\ Katsuya Takanashi
}

\begin{abstract}
This study investigates how different segments of the public, with varying degrees of interest in S\&T, could formulate opinions on a broader vision and the role they think STI should play in Japanese society through 2020 (Tokyo's Olympic and Paralympic year) and toward 2030. We conducted nine inclusive public engagement activities. Results indicated that the broad public opinions did not completely overlap with officials' opinions, a value of "open and appropriate" was mainly found from the unengaged public, and the visions and values based on their opinions could well be incorporated into the official document. Engaging the disinterested in S\&T remains an issue.
\end{abstract}

Keywords

Participation and science governance; Public engagement with science and technology; Science and policy-making

DOI

https://doi.org/10.22323/2.18030202

Submitted: 29th June 2018

Accepted: 18th January 2019

Published: 14th June 2019

Introduction

Many countries are shifting their science and technology (S\&T) policies to science, technology, and innovation (STI) policies. In a 2014 survey by the European Commission/OECD international survey on Science, Technology, and Innovation Policies (STIP) on STI policies, 53 countries — including emerging economies (e.g., Brazil, the People's Republic of China, India, Indonesia, the Russian Federation, and South Africa), which account for an estimated $97 \%$ of global research and development $(R \& D)$ - have already developed their STI policies [Organisation for Economic Co-operation and Development, 2014]. In Japan, the seeds of technologies were largely emphasized in S\&T policy until the period of the3rd Science and Technology Basic Plan (FY2006-2010), whereas, the public need for technologies was given more importance in STI policy to realize the backcasting 
policy making process from the desirable society after the 4th Science and Technology Basic Plan (FY 2011-FY 2015). STI comprises the complete spectrum of creating intellectual and cultural value based on new knowledge from scientific discoveries and inventions, and technology advancement that expands this information to create economic, social, and public value [Council for Science, Technology and Innovation, 2017]. Thus, creating public values, that is, the public need for technologies, is important for innovation. In Japan, there are higher expectations for STI, in the country's bid to adapt to economic and societal changes and solve complicated social issues, such as the emergence of an aging society with low birth rate [Council for Science, Technology and Innovation, 2017]. Therefore, the shift from S\&T to STI policies has been strengthened in the national STI plan, the 4th Science and Technology Basic Plan, and this trend will continue for the next five years of the 5th Basic Plan. To make the STI policy formation more evidence-based and transparent to the public, the Japanese government has been promoting the Science for Re-designing Science, Technology and Innovation Policy (SciREX) program since 2011. ${ }^{1}$ Under the SciREX program, we have been developing a public engagement project called the Framework for Broad Public Engagement in Science, Technology, and Innovation Policy (PESTI) since 2012. This project aims to reflect the views of the public in STI policy-making and ensure fairness and transparency [Kano, 2014]. In this work, we define the term "public engagement" as a two-way communication providing citizens an opportunity to hear about decisions that affect them so that they can voice their concerns if any or provide support to decision makers [Besley, 2010] and use the term interchangeably with public participation because the former term is increasingly favored over the latter in the S\&T studies field [Delgado, Kjølberg and Wickson, 2011].

Objective of the study: how the diverse segments of the public formulate visions and place STI in these visions

The objective of this study is investigating how different segments of the public, with varying degrees of interest in S\&T could formulate opinions on a broader vision and the role they think STI should play in the visions for society through 2020 (Tokyo's Olympic and Paralympic year) and toward 2030 in Japan. The Olympic Paralympic year has been taken as an opportunity to develop a future vision for Japan. The vision does not exclusively focus on STI, but we asked the participants in the public engagement activities to give their opinions on possible STI developments as well. We also discover the values based on their opinions, because values are important for innovation as mentioned before. Thus, the study focuses on how STI can be part of a desirable society, not how society should respond to STI.

In order to collect and analyze opinions from the public, we developed a public engagement method called interactive public comment, which combines a public comment system and dialogue-based activities, for the purpose of realizing more inclusive public engagement in policy [Kano, 2014]. We have conducted nine interactive public comment activities on the future vision. We have had two chances of being involved in the process of policy making: Japan Vision 2020 published in January 2014 by the Ministry of Education, Culture, Sports, Science and Technology (MEXT) and the Olympic Paralympic Legacy plan in April 2015 by

\footnotetext{
${ }^{1}$ More details are available at https:/ / scirex.grips.ac.jp/en/.
} 
the MEXT. The result of the only interactive public comment activity could be for Japan Vision 2020, because time was limited in publishing Japan Vision 2020, whereas the result of all activities could be utilized for the Olympic Paralympic Legacy plan. An overview of the research is as shown in Figure 1.

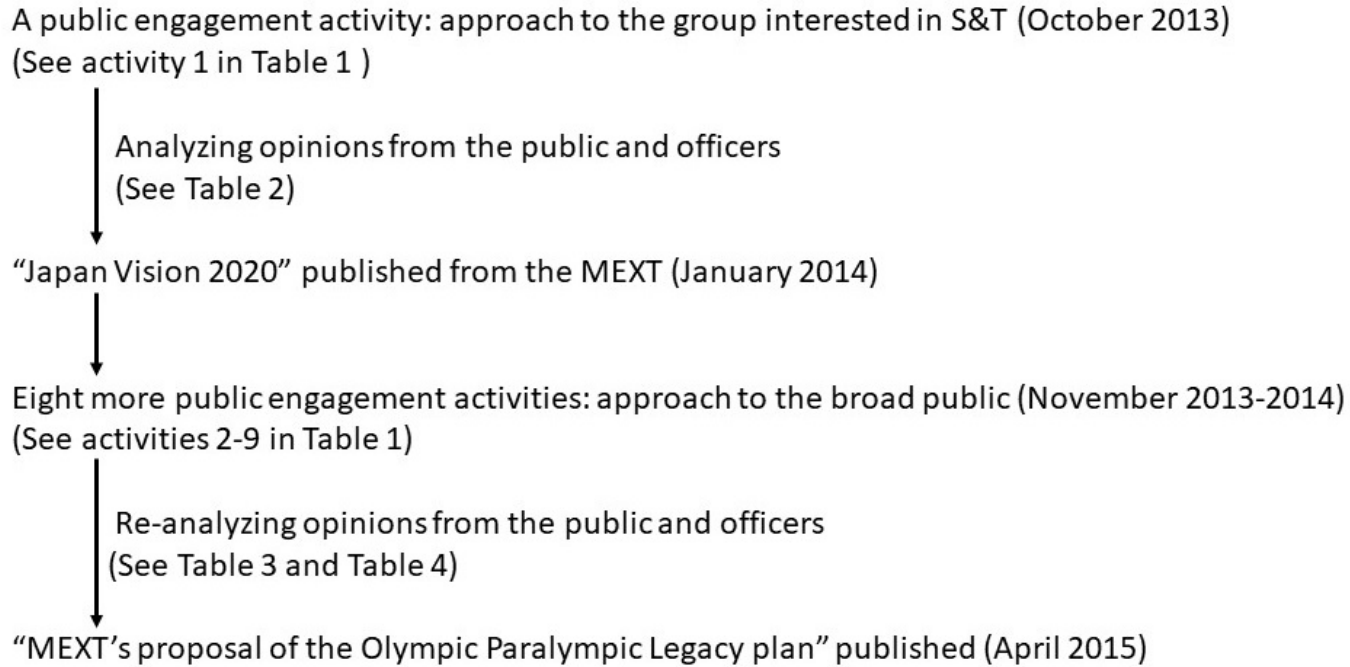

Figure 1. Overview of the research.

In order to develop and implement our public engagement activities, we emphasized more open policy making and inclusiveness of the activities, because this study investigates how the diverse segments of the public, including the unengaged, formulate visions and place STI in those visions.

\section{More open policy making}

In Europe, over the last two decades, policy discourse on science-society issues has shifted from information politics and monitoring of citizens (1989-), raising awareness of S\&T (late 1990s-), dialogue, participation, and governance with respect to science and society (early 2000s-), and science in society (2007-2013), to innovation union 2020: responsible research and innovation [Floud et al., 2013]. A similar shift has happened in Japan: public understanding of science (1996-), public participation in S\&T (2006-), and development of policy created together with society (2011-). The PESTI project was laid out during the latest era.

In accordance with this shift, the model of expertise has rapidly moved from the old closed type to the new open policy. The old model of expertise is "closed, homogenous, hubristic, demanding public trust, expecting expert consensus and prescription, managerial control and presenting the evidence," whereas the new model is "open, diverse, humble, trusting the public, expecting plural and conditional advice, distributed control and presenting evidence, judgement and uncertainty" [Stilgoe and Burall, 2013, p. 96].

In this stance toward open policy, there has been a shift from engaging individuals who represent organized groups within society to engaging lay citizens directly. Of course, the representatives in organized groups are also citizens. However, "there 
is a compelling analytical distinction" [Smith, 2009, p. 2]. This distinction relates to the issue of who should be included in public engagement [Delgado, Kjølberg and Wickson, 2011].

Public dialogue is especially oriented towards including or giving voice to people who seem to be unengaged, or who perceive themselves to be unaffected by concrete science and technological developments. Such latent publics are generally valued by dialogue organizers for not having preexisting or established views on a particular issue. [Mohr, Raman and Gibbs, 2014, p. 9]

Thus, the diversity of the lay public, including the unengaged, is important for a more open policy. Floud et al. [2013] pointed out diversity has remained an issue to making innovation more responsive to broader values and expectations. However, including the unengaged in policy-making has proven challenging. A practice conducted by the Department of Energy and Climate Change (DECC) in the U.K. is a good example for engaging teenagers or disillusioned residents who are regarded as the unengaged [Department of Energy and Climate Change, 2012].

\section{Inclusiveness of public engagement practices}

When considering the practices of public engagement, consideration should be given to two aspects of inclusiveness: how to select participants in public engagement activities and how much participants are able to contribute to a policy making process [Smith, 2009, p. 163]. First, in terms of selection of participants, comprehensive citizen engagement should be realized. However, the issue of unequal participation persists [Lijphart, 1997]. In this situation, appointment of the unengaged could be worthy of consideration [Smith and Stephenson, 2005], although appointment remains an issue because the selection criteria and process are typically controlled [Smith, 2009, p. 167]. Second, the participants' opinions have to be properly incorporated into policy decision-making. However, in the U.K., only one-third of local authorities reported feeling that public participation has a significant outcome on final decision-making [Lowndes, Pratchett and Stoker, 2001, p. 452]. The same has been observed in Japan. The expert survey on the Japanese S\&T and innovation system, conducted by the National Institute of Science and Technology Policy (NISTEP) of MEXT in Japan, also showed that experts regarded multi-stakeholder engagement including the public engagement as insufficient [National Institute of Science and Technology Policy, Ministry of Education, Culture, Sports, Science and Technology, 2018]. One of the reasons is that in representations of the public, the public is viewed as "a naïve, childlike and clamorous public; and/or as lacking skills, capacities or trust" [Newman et al., 2004, p. 210].

\section{Who are the unengaged}

To promote inclusive public engagement, the diversity of the public needs to be understood; surveys on public attitudes to S\&T are thus beneficial [Cormick, 2012]. For example, surveys conducted in the U.K. since 2000 have shown that the British population could be segmented into six distinct categories of similar attitudes to science: confident engagers, distrustful engagers, late adopters, concerned, 
disengaged skeptics, and indifferent [Castell et al., 2014, p. 134]. A 2012 survey in Australia categorized the public into "the concerned and disengaged," "the risk averse," "the cautiously keen," and "the science fans" [Cormick and Romanach, 2014]. Meanwhile, surveys conducted in Victoria, Australia, showed that the population could be segmented into six distinct groups with varying interest levels in S\& $\mathrm{T}^{2}$ [Victorian Department of Innovation, Industry and Regional Development, 2011]. Thus, nationwide or region-wide surveys help in the reinterpretation of the public as several segments, each having different levels of interest in S\&T policies.

By applying the segmentation method of Victoria, Australia, to on-site surveys, we confirmed that although S\&T events, such as science cafés, science festivals, and public lectures, are not always intended for the higher-interest public, they generally attract attendance by this group. However, members of the lower-interest public do not typically attend such activities [Kano et al., 2013]. Moreover, segments with higher levels of interest are highly intrinsically motivated to attend both small- and large-scale S\&T events [Goto, Mizumachi et al., 2014] and highly motivated to engage in policy-making; they also tend to have a greater internal sense of political efficacy [Goto, Kudo and Kano, 2015]. These findings suggest the difficulty in engaging those with low interest in S\&T. In the present study, we combined segments in the Victorian survey based on previous findings showing segments responding similarly [Goto, Mizumachi et al., 2014; Goto, Kudo and Kano, 2015]. Subsequently, the combination of segments A and B was set as the "group of people with interest in science and technology," the combination of $C, D$, and $\mathrm{E}$ as the "group of people with potential interest in science and technology," and segment $\mathrm{F}$ as the "group of people with low interest in science and technology." In this study, we regarded the "group of people with potential interest in science and technology" and the "group of people with low interest in science and technology," that is, segments C, D, E, and F, as the unengaged in science and technology.

We conducted public engagement activities connected to STI policy-making, under the term "interactive public comments," in which broad segments of people expressed their opinions in a dialogue-based activity on a specific issue related to STI, using the manual of facilitation we developed. In such activities, the organizer delivers the comments to policy-makers as public comments [Kano, 2014].

Soon after Olympic Paralympic 2020 was determined to be held in Tokyo on September 2013, we held an interactive public comment activity on October 2013 (activity 1 in Table 1), as part of "Japan Vision 2020," or the vision through 2020 (Olympic and Paralympic year in Tokyo) and toward 2030 in Japan. In the activity, we asked the following three questions.

\footnotetext{
${ }^{2}$ The original segment numbers are $2,3,1,6,4$, and 5 in order of high interest to low interest levels. The segment numbers and the degree of interest in science and technology do not correspond to each other, as the numbers were automatically allocated while developing the segments [Victorian Department of Innovation, Industry and Regional Development, 2011]. In this paper, we use segments A, B, C, D, E, and F, instead of segments 2, 3, 1, 6, 4, and 5 .
} 
Table 1. Types of interactive public comment activities and the rate of the group interested.

\begin{tabular}{|c|c|c|c|c|c|}
\hline No. & Dates & $\begin{array}{l}\text { How to approach the } \\
\text { participants }\end{array}$ & $\begin{array}{l}\text { Dialogue or face-to- } \\
\text { face questionnaire }\end{array}$ & $\begin{array}{l}\text { Number of interested : potentially } \\
\text { interested : disinterested : N/A }\end{array}$ & $\begin{array}{l}\text { Response } \\
\text { rate }(\%)\end{array}$ \\
\hline 1 & Oct. 28,2013 & Open recruitment & Dialogue & $13: 1: 0: 11(\mathrm{n}=25)$ & 56.0 \\
\hline 2 & Nov. 9-10, 2013 & Access to scientific events & Face-to-face questionnaire & $0: 0: 0: 9(\mathrm{n}=9)$ & 0 \\
\hline 3 & Dec. 21-22, 2013 & Access to scientific events & Face-to-face questionnaire & $29: 9: 0: 8(n=46)$ & 82.6 \\
\hline 4 & Feb. 2, 2014 & Access to scientific events & Face-to-face questionnaire & $18: 13: 0: 0(\mathrm{n}=31)$ & 100 \\
\hline 5 & Nov. 23, 2013 & Access to non-scientific events & Face-to-face questionnaire & $10: 21: 4: 2(\mathrm{n}=37)$ & 94.6 \\
\hline 6 & Aug. 9-10, 2014 & Access to non-scientific events & Face-to-face questionnaire & $0: 0: 0: 5(n=5)$ & 0 \\
\hline 7 & Jul. 9, 2014 & Access to non-scientific events & Dialogue & $0: 5: 0: 0(\mathrm{n}=5)$ & 100 \\
\hline 8 & Jul. 25, 2014 & $\begin{array}{c}\text { Access to non-scientific events } \\
-\end{array}$ & Dialogue & $0: 10: 0: 1(\mathrm{n}=11)$ & 90.9 \\
\hline \multirow[t]{2}{*}{9} & Jul. 21, 2014 & $\begin{array}{l}\text { *Recruitment through marketing } \\
\text { research company }\end{array}$ & Dialogue & $0: 3: 2: 0(\mathrm{n}=5)$ & 100 \\
\hline & & & Total & $70: 62: 6: 36(n=174)$ & \\
\hline
\end{tabular}

Q1. What recommendations and issues in Japan required emphasis?

Q2. What do you wish Japan would be like through 2020 (Olympic and Paralympic year in Tokyo) and toward 2030?

Q3. How do you think science and technology will contribute to realizing the future vision you mentioned?

These questions were intended to ask the public for their vision of a desirable society and to give their opinions on how STI can play a role in broader visions for a desirable society as well. At the same time, the Japan Vision 2020 team in the MEXT held a dialogue workshop and gathered their opinions on Japan Vision 2020, in order to compare the opinions from the public with those from the officers.

\section{Grouping opinions}

With the permission of the participants in the public engagement activity, we recoded their opinions as short sentences (codes). Opinions from the MEXT officers were coded as well. The codes were grouped into several larger groups, partially using the $\mathrm{KJ}$ method, a technique for analyzing qualitative data derived from Japanese ethnology named after Japanese cultural anthropologist Kawakita Jiro [Scupin, 1997]. Following the method, we conducted three steps: 1) we coded the opinions and copied the codes on note cards; 2 ) we shuffled the codes (note cards) and grouped them into the larger groups; 3 ) we assigned titles for all the larger groups of codes.

\section{Linking technologies to the larger groups of codes}

We linked technologies, which were predicted to be realized in 2020, according to the NISTEP of MEXT's Delphi surveys. We obtained the list of technologies from the NISTEP of MEXT, for the larger groups of codes. The list included 142 technologies in 14 categories: autonomous vehicles; infrastructure management; 
risk management; prediction of disaster, electricity, and information infrastructure; energy management; energy usage; zero emission; digital fabrication; technical tradition; inclusive society; service science; food and health; and life science. Examples of technologies are telexistence technology for people to remotely feel distant places with their five senses; biometrics authentication technology, for travel abroad without the use of passports; automatic translation system using machine learning; prediction of natural disasters such as torrential rain an hour before occurrence; artificial arms and legs with sensory function; and autonomous driving in special lanes.

\section{Public engagement activities: approach to the broader public}

We held eight more interactive public comment activities from 2013 to 2014 (activities 2 to 9 in Table 1), in order to investigate how the broader public, including the unengaged, formulate visions and place STI in these visions. The activities were part of forming the Olympic Paralympic Legacy plan by MEXT, which was the next step of Japan Vision 2020, covering the longer-term benefits and effects of planning, funding, building, and staging the Olympic and Paralympic Games. We determined that, to approach the broader segments of the public, accessing the sites frequented by people was more effective than conducting open recruitment. Therefore, we actively accessed scientific and non-scientific events. We conducted two types of activities: dialogue workshop and face-to-face questionnaire survey (Table 1). We also attempted to access the unengaged, the group of people with potential or low interest in S\&T (segments C, D, E, and F). In all the activities, we asked the same three questions as activity 1.

At the same time, the Japan Vision 2020 team gathered opinions from the officers by e-mail questionnaire to form the Olympic Paralympic Legacy plan. In parallel, the Tokyo organizing committee for the Olympic and Paralympic Games and cabinet meeting for the same were launched in 2014. They released a speculative draft for the Olympic Paralympic Legacy and action plan to relevant ministries. We obtained opinions from the e-mail questionnaire, as well as from the disclosed official documents of the Tokyo organizing committee and cabinet meeting.

\section{Re-grouping Opinions}

We collected public opinion through the successive public engagement activities, as well as officers' opinions. Therefore, we conducted a re-grouping of the opinions. First, we situated all of the opinions into the existing groups or "others." Second, we formed new groups out of the opinions in "others." Finally, we re-situated all of the opinions into the groups, including the new groups, and then ensured that no new groups could be formed from "others." Public opinions (events, group interest in $\mathrm{S} \& \mathrm{~T}$ ) were blinded, in terms of source. The blinding was released after the process.

Two researchers were involved in the process. First, each researcher conducted the re-grouping independently. Second, each researcher cross-checked the groupings. Third, the researchers collaborated to improve the grouping and find new groups by mutual agreement. Finally, each researcher conducted the re-grouping independently and cross-checked them. 


\section{Identifying the population and profile of the unengaged by an opinion poll}

In order to obtain the basic information on the population and profile of the public with different degrees of interest in S\&T, we conducted an opinion poll on public needs/opinions and involvement in STI policy, to foster the development of a social system in which the public can widely participate in policy-making. We already had preliminary information from an internet survey [Kano, 2014], but thought we should obtain more precise information from the face-to-face survey, which covered all regions of Japan. The target of the survey was Japanese citizens aged at least 16 years; the sample, identified through stratified two-stage random sampling, comprised 2,000, of which 887 returned valid responses $(44.4 \%)$. The survey was conducted on December 12-23, 2013. The survey evaluated the following key points: (1) interest, understanding, and information gathering regarding S\&T; (2) subjective evaluation of citizens' influence on the formation of policies on STI; (3) various policies in Japan, and citizens' interest in and evaluation of S\&T innovation; (4) organizations/persons/partnerships that contribute to the advancement of S\&T; (5) attitude toward new technologies and new products; and (6) lifestyle. All of the materials, including the survey questionnaire, raw data (Excel and SPSS), and infographics of the results, can be downloaded from the website of NISTEP of MEXT. ${ }^{3}$

We used the segmentation method developed by the Victorian survey, which classifies the public with different interests in S\&T into six segments (A, B, C, D, E, and $\mathrm{F}$ ) and three different groups (people with interest, potential interest, or low interest in S\&T) mentioned in the introduction section. The six segments and three groups were determined using a decision tree from different combinations of answers to the following three questions (Table 5).

Q1. How much are you interested in science and technology?

Q2. Do you actively search for information on science and technology?

Q3. In the past, when looking for information on science and technology, have you generally been able to find what you were looking for?

Subsequently, we created the profiles of each segment, using the items statistically different from those of other segments.

\section{Results and discussion}

How the group interested in SET formulate visions and how STI can be part of the visions

We broadly announced a public engagement activity and openly recruited 25 participants (activity 1 in Table 1). The participants were mainly in the group of interested individuals (13 out of 14, except N/A). Upon obtaining the opinions from the officers, we analyzed the collected opinions from both the public and the officers and grouped them into several larger groups. Consequently, we identified four main values as the larger groups, namely, "ties with others and diversity," "safety and security," "Japanese pride," and "comfort, efficient, and convenient

\footnotetext{
${ }^{3}$ http:/ / www.nistep.go.jp/en/?page_id=3867.
} 
society," and two sub-values as the sub-larger groups, namely, "exciting and cool" and "leeway." An opinion was not always grouped into a single value; opinions may also be grouped into main and sub-values simultaneously. The distribution of opinions from the 25 participants in activity 1 and the officers are shown in Table 2. The chi-squared test revealed no significant differences. Every value included both opinions from the public and the officers. Based on this result, the opinions of the interested public reflected those of the officials. Collaborating with the Japan Vision 2020 team, we then introduced three future visions: "inspiration," "dialogue," and "maturity," based on the six values. Finally, the official document "Japan Vision 2020" [Ministry of Education, Culture, Sports, Science and Technology, 2014], including three future visions and six values, was published in January 2014.

Table 2. Values found from the opinions of the 25 participants in activity 1 and the officers, and the number of technologies around 2020 as foreseen by the Delphi survey.

\begin{tabular}{|lcccc|}
\hline \multicolumn{1}{|c}{ Values } & $\begin{array}{c}\text { Total number of } \\
\text { opinions }\end{array}$ & $\begin{array}{c}\text { Number of } \\
\text { opinions } \\
\text { from the public }\end{array}$ & $\begin{array}{c}\text { Number of } \\
\text { opinions } \\
\text { from the officers }\end{array}$ & $\begin{array}{c}\text { Number of } \\
\text { technologies in } \\
\text { around 2020 }\end{array}$ \\
\hline 1: Ties with others and diversity & 23 & 12 & 11 & 13 \\
2: Safety and security & 10 & 9 & 1 & 5 \\
3: Japanese pride & 10 & 5 & 5 & 4 \\
4: Comfortable, efficient, and convenienty society & 20 & 14 & 6 & 16 \\
5: Exciting and cool & 13 & 6 & 7 & 4 \\
6: Leeway & 6 & 4 & 2 & 4 \\
Others & 56 & 33 & 23 & - \\
\hline
\end{tabular}

Subsequently, we linked technologies, which were predicted to be realized in 2020 to the values. The S\&Ts linked with the values are shown in Table 2 . As a result, we could link each value from "1: ties with others and diversity" to "6: leeway" with the S\&Ts in 2020 as predicted by the Delphi survey. Given this link, the values found in the present study are not removed from the STI policy process. In fact, the values and foresighted STI were incorporated into an official document on Japan Vision 2020 and the examples of STI mentioned above were covered in the top stories of a newspaper in 2014 that said the Japanese government planned to accelerate S\&Ts.

\section{How the broader public with different interest in SET formulate visions}

We accessed scientific events three times and non-scientific events four times to select the unengaged and take their opinions (segments C, D, E, and F). Moreover, considering the profiles of the unengaged, targeting females appeared to be a better way to access the potentially interested and disinterested groups because members of the highest interested segment A are more likely to be male, whereas members of the lowest interested segment $\mathrm{F}$ are more likely to be female, with the rate of males gradually decreasing between segments A and F (Table 5). Exceptionally, we recruited the unengaged through a marketing research company. We held face-to-face surveys five times and dialogue activities three times. There were 149 participants in all. Table 1 shows the rate of attendance of the interested, potentially interested, and disinterested groups in each event. In comparing the activities, we found that accessing the non-scientific events yielded a lower rate of the interested group compared with scientific events. In activities 7 and 8 especially, we accessed 
the parents and teachers of a kindergarten and the PTA of an elementary school, respectively, because the attending people are likely to be female and homemakers, as suggested by the profiles of the disinterested. Meanwhile, in activity 5, we accessed a civic group in which people presented proposals for local policy on non-scientific themes. In activity 6 , we accessed a commercial facility. Unexpectedly, the facility officers limited the interaction area, and so our approach could not succeed. As a result, we could access the interested, potentially interested and disinterested public (70, 62 and 6 out of 174 respectively; see Table 1$)$. In all, we collected 477 opinions from the broad public through 9 activities.

In parallel, we obtained 478 officers' opinions from an e-mail questionnaire as well as from the disclosed official documents of the Tokyo organizing committee and cabinet meeting.

We re-grouped these opinions and identified the new value of "open and appropriate." We also grouped opinions into "measures and others," because many opinions referred to detailed measures, and not to the vision. Again, an opinion was not always grouped in a value. This result was referenced by MEXT in forming the Olympic Paralympic Legacy plan. The official document "MEXT's proposal of Olympic Paralympic Legacy plan" was published on April 10, 2015.

Table 3. Values found from the opinions of the 174 broad participants in the 9 activities and the officers.

\begin{tabular}{|lccr|}
\hline \multicolumn{1}{|c}{ Values } & $\begin{array}{c}\text { Total number of } \\
\text { opinions }\end{array}$ & $\begin{array}{c}\text { Number of } \\
\text { opinions } \\
\text { from the public }\end{array}$ & $\begin{array}{c}\text { Number of opinions } \\
\text { from the officers }\end{array}$ \\
\hline 1: Ties with others and diversity & 358 & 153 & 205 \\
2: Safety and security & 204 & 148 & 56 \\
3: Japanese pride & 314 & 113 & 201 \\
4: Comfortable, efficient, and convenienty society & 354 & 239 & 115 \\
5: Exciting and cool & 318 & 104 & 214 \\
6: Leeway & 215 & 166 & 49 \\
7: Open and appropriate & 13 & 12 & 1 \\
Others: Measures & 225 & 19 & 206 \\
Others: Others & 291 & 151 & 140 \\
\hline
\end{tabular}

The distribution of the number of opinions from the 174 participants in the 9 activities and officers is shown in Table 3. The chi-squared test we conducted revealed significant differences $(\mathrm{p}<0.01$ ). This result suggested that public opinion did not completely overlap the opinion of the officials. Therefore, the public opinions would be important for formulating visions. Values 2, 4, 6, and 7 consisted of more public opinions, whereas values 1,3, and 5 consisted of more officers' opinions. It is especially interesting that Value 7 consisted of many more public opinions, as shown in Table 4, and we found that many opinions in Value 7 were from the activities where the attendance rate of the interested group was low (activity nos. 5, 7, 8, and 9). This result suggested that the unengaged public did not completely agree with both the interested group and the officials. In fact, this value 7 appeared to be important. Toward Olympic and Paralympic 2020, two problems relating to the "open and appropriate" occurred in Japan in 2015. One problem was the alleged plagiarism of the emblem of the Olympic and Paralympic Games, which was similar to an existing logo in Belgium. As a result, the emblem 
was retracted and renewed in 2016. Among the issues that arose was that the process of selecting the emblem was not open to the public. Therefore, in renewing the emblem, the process became more open. The other problem was that the cost of building the new national stadium was quite expensive at USD 3 billion. The cost was regarded by the public as inappropriate. After a long discussion within the government, the original plan was rejected, and a more appropriate plan costing USD 1.5 billion was approved. In the process of renewing the plan, the MEXT minister took accountability for the problem and resigned. These problems are not related directly to the STI policy for the Olympic and Paralympic 2020. However, some opinions in the value "open and appropriate" were mentioned to S\&T (for example, a need for further understanding and investigation of both merits and limits of S\&T). Therefore, this value was thought to be important for open process and appropriate cost related to STI policy.

Table 4. Opinion list and the activities where the opinions come from, in the value 'open and appropriate'.

\begin{tabular}{|rlr|}
\hline No. & Opinions (Open and appropriate) & $\begin{array}{c}\text { Activity } \\
\text { no. in } \\
\text { Table } 3\end{array}$ \\
\hline 1 Prioritize and make good use of taxes. Change from policy that puts the economy ahead of all else. & 3 \\
2 Want to know more about how S\&T works. & 4 \\
3 Need for further understanding and investigation of both merits and limits of S\&T. & 5 \\
4 There are ethical issues of S\&T. & 5 \\
5 Smoothly organize the Olympics and Paralympics. & 7 \\
6 Think about the legacy for children after Olympics and Paralympics. & 7 \\
7 Visualize the figures to ensure practical understanding of information. & 8 \\
8 Tell us the use of consumption taxes, when the tax rate will increase. & 9 \\
9 & Announce officially how the national budget was used. & 9 \\
10 & Visualize politicians' promises. & 9 \\
11 & Make good use of taxes. & 9 \\
12 & The public should oversee the national budget. & 9 \\
13 & Examine the outcomes and issues of the policy measures, based on evidence. & Officers \\
\hline
\end{tabular}

\section{Population and profile of the segments}

The population of the segments, based on the 2012 internet research [Kano, 2014], was updated based on the opinion poll. Table 5 shows the segment sizes of the Japanese population and the corresponding sample in Victoria, Australia, in our opinion poll. There were significant differences between them $(\mathrm{p}<0.01$, chi-squared test). The rate of those interested in science and technology (16\%) was much less compared with that in Victoria, Australia (53\%). We thought that the results were not surprising because the Japanese have better skills to answer science tests, but are less interested in science. The results of the program for international student assessment (PISA) showed that Japanese students have been strong performers in scientific literacy. For example, in PISA 2015, the Japanese scored 538 points in science, outperformed only by Singaporean students (556 points) and comparable to Estonia (534 points) and Taiwan (532 points) [Organisation for Economic Co-operation and Development, 2016]. Nevertheless, the results of PISA also showed that the Japanese level of enjoyment in science has been below the OECD average, coming in at the second lowest in 2015 [Organisation for Economic 
Co-operation and Development, 2016]. This tendency of moving away from the S\&T phenomenon was first known in 1993 [Ministry of Education, Culture, Sports, Science and Technology, 1993] and has continued thus far.

Table 5. Decision tree of segments and groups according to their interest in S\&T and the population of Victoria, Australia, and Japan.

\begin{tabular}{|c|c|c|c|c|c|c|}
\hline $\begin{array}{l}\text { Q1: Interest in } \\
\text { science }\end{array}$ & $\begin{array}{l}\text { Q2: Actively } \\
\text { search for } \\
\text { info }\end{array}$ & $\begin{array}{l}\text { Q3: Success in } \\
\text { finding info }\end{array}$ & Segments & $\begin{array}{c}\text { Victoria, } \\
\text { Australia } \\
\text { (2011) }\end{array}$ & $\begin{array}{l}\text { Japan } \\
\text { (2013) }\end{array}$ & Groups \\
\hline Very or quite & Yes & $\begin{array}{l}\text { Yes, easy to } \\
\text { understand }\end{array}$ & A & $37 \%$ & $8 \%$ & \\
\hline Very or quite & Yes & $\begin{array}{c}\text { Yes, but } \\
\text { difficult to } \\
\text { understand } \\
\text { No, can't find } \\
\text { it }\end{array}$ & B & $16 \%$ & $8 \%$ & Interested \\
\hline Very or quite & No & - & $C$ & $19 \%$ & $29 \%$ & \multirow{3}{*}{$\begin{array}{c}\text { Potentially } \\
\text { interested }\end{array}$} \\
\hline $\begin{array}{c}\text { Neutral, not } \\
\text { very or not at } \\
\text { all }\end{array}$ & Yes & - & D & $6 \%$ & $4 \%$ & \\
\hline Neutral & No & - & E & $9 \%$ & $29 \%$ & \\
\hline $\begin{array}{c}\text { Not very or not } \\
\text { at all }\end{array}$ & No & - & $\mathrm{F}$ & $13 \%$ & $23 \%$ & Disinterested \\
\hline
\end{tabular}

Table 6 presents the sample profiles, based on demographics (age, sex, occupation, income, educational background, and living region) and information source on $S \& T$, to enable segment targeting in public engagement. Profiles consisted of the items of the significantly largest number of the population compared with other segments; percentages were computed by dividing the frequencies of respondents by the number of all respondents in each segment. For example, the profile "Male $(72.5 \%)^{\prime \prime}$ in segment A shows that $72.5 \%$ of segment A are male and the population is significantly the largest. Infographics of the profiles can be downloaded from the website of NISTEP within MEXT. ${ }^{4}$ This shows that the rates of males gradually decreased from the highest interested segment $A$ to the lowest interested segment F. Therefore, when targeting females, we were more likely to access the potentially interested. Using profiles to target a segment is a popular method in marketing research and well known as the STP (Segmentation, Targeting, and Positioning) method. The method has been introduced to the public sector and called "social marketing" [Kotler and Lee, 2007].

Future perspective Finally, we discussed the limitations and future perspectives on four points: how the broad public could formulate opinions on a broader vision and the role they think STI should play in the visions, the effect on decision-making, access to the broader public, and transparency.

First, our results showed that the broad public opinions did not completely overlap with those of the officials, whereas there was no significant difference between the

\footnotetext{
${ }^{4}$ http://www.nistep.go.jp/en/wp-content/uploads/Infographics_VictorianSegments.pdf.
} 
Table 6. Profiles of segments.

\begin{tabular}{|c|c|c|}
\hline Groups & Segments & Example of profiles \\
\hline \multirow{12}{*}{ Interested } & \multirow{9}{*}{ A } & - Male $(72.5 \%)$ \\
\hline & & - 30 s $(20.3 \%)$ \\
\hline & & - Educational background of graduate school \\
\hline & & - Management position (13.0\%) \\
\hline & & - Specialist/Technical work (26.1\%) \\
\hline & & - Family income: USD 8,000 to $10,000(13.0 \%)$, USD 10,000 to $15,000(8.7 \%)$, and over USD \\
\hline & & $15,000(5.8 \%)$ \\
\hline & & - Newspaper or magazine $(87.0 \%)$, books $(47.8 \%)$, library $(21.7 \%)$, symposiums, lectures, or events \\
\hline & & at universities and research institutions $(21.7 \%)$ as source of S\&T information \\
\hline & \multirow{3}{*}{ B } & - Educational background of bachelor's degree (43.3\%) \\
\hline & & - Living in small city $(35.8 \%)$ \\
\hline & & - Science museum or museum as source of S\&T information $(19.4 \%)$ \\
\hline \multirow{8}{*}{$\begin{array}{l}\text { Potentially } \\
\text { Interested }\end{array}$} & & - Unemployed (18.7\%) \\
\hline & $\mathrm{C}$ & $\begin{array}{l}\text { - TV }(89.6 \%) \text {, radio }(18.3 \%) \text {, promotion event at companies, advertisement, catalogues }(18.7 \%) \text { as } \\
\text { source of S\&T information }\end{array}$ \\
\hline & \multirow{4}{*}{$\mathrm{D}$} & - $20 \mathrm{~s}(18.9 \%)$ \\
\hline & & - $40 \mathrm{~s}(32.4 \%)$ \\
\hline & & - Self-employed (10.8\%) \\
\hline & & - Internet as source of S\&T information $(78.4 \%)$ \\
\hline & \multirow{2}{*}{$\mathrm{E}$} & • $50 \mathrm{~s}(25.3 \%)$ \\
\hline & & - Manual labor (20.7\%) \\
\hline \multirow{5}{*}{ Disinterested } & \multirow{5}{*}{$\mathrm{F}$} & - Female $(67.0 \%)$ \\
\hline & & - Over $70 \mathrm{~s}(31.4 \%)$ \\
\hline & & - Educational background of high school (50.3\%) \\
\hline & & - Educational background of elementary/junior high school (24.1\%) \\
\hline & & - Housekeeper $(27.7 \%)$ \\
\hline
\end{tabular}

distribution of opinions from the public and the officers. Moreover, we found that a value of "open and appropriate" was mainly from the opinions taken at the public engagement activities where the unengaged participated (Activities 7, 8, and 9 in Table 1). This indicates that including the unengaged as well is important for taking the opinions or values that do not overlap with those from the interested group into consideration for the policy making process. In addition, from the viewpoint of innovation, creating values is important. Therefore, linking values and S\&T is important for making STI policy. In the study, we succeeded in linking values found in this study with the S\&Ts in 2020 as predicted by the Delphi survey, which means we could make STI policy. As such, the broader public opinions could formulate values or visions and place possible STI developments in these values or visions.

Second, we found that public opinions could affect the drafting of official documents: almost all of the visions and values and some possible STI developments were incorporated into "Japan Vision 2020" and MEXT's proposal of the Olympic Paralympic Legacy plan. However, the value "open and appropriate" was not incorporated into the official document, because the MEXT officers questioned the importance of the value. Moreover, the official documents only partially affected the decision-making process. The Japanese government announced a plan to adopt the examples of S\&T in Japan Vision 2020; however, the 
documents from MEXT have been referenced in the process toward and after the Olympic Paralympic Games. This is because there are many stakeholders, such as the IOC, JOC, The Tokyo Organising Committee of the Olympic and Paralympic Games, and the Tokyo metropolitan government, even if their main affairs are not focused on STI. Therefore, for the success of incorporating the public voice into decision-making, we needed to engage the stakeholders.

Third, our study suggested that the social marketing approach could be effective in accessing the unengaged. The results confirmed previous ones on an appointment approach [Smith and Stephenson, 2005]. However, the approach to the disinterested people remains an issue requiring a novel approach, because we could not approach them without activity 5 (see Table 1).

Fourth, we emphasized transparency, which meets the value of "open and appropriate." We actively published the history of making the official documents. We held a public symposium with the officers on the process of Japan Vision 2020. We also established a website ${ }^{5}$ through which everybody could see the process of our interactive comment activities and of drafting official documents, trace the process of grouping opinions to the values, and search the public's and officers' opinions, including to which values an opinion belonged. We thought the symposium and website could visualize the process of how the broad public could formulate visions and values, and place STI within them.

Finally, our results suggested that dialogue with the broad public including the unengaged, to find public needs or values for innovation, plays an important role in STI policy making process as backcasting from a desirable society. However, there have hardly been any experiences to draw from in such a desirable-society-driven STI policy making process. Science communication practitioners and researchers on such a STI policy making process and STI policy making practitioners will need to share and analyze examples of practices and the results of public engagement.

Acknowledgments We would like to thank the public involved in our public engagement activities and all the members of the Japan Vision 2020 team in MEXT, especially in the team leader Mr. Takuya Saito, and Public Comment Promotion Group. We also would like to thank Editage for the English language editing. This work was supported by the Research Institute of Science and Technology for Society, Japan Science and Technology Agency.

References

Besley, C. J. (2010). 'Public engagement'. In: Encyclopedia of science and technology communication. Ed. by H. S. Priest. Thousand Oaks, CA, U.S.A.: SAGE Publications, pp. 603-608.

Castell, S., Charlton, A., Clemence, M., Pettigrew, N., Pope, S., Quigley, A., Shah, J. N. and Silman, T. (2014). Main report: public attitudes to science 2014. URL: https://www.ipsos.com/sites/default/files/migrations/en-uk/file s/Assets/Docs/Polls/pas-2014-main-report-accessible.pdf (visited on 21st June 2018).

\footnotetext{
${ }^{5}$ http:/ / interactive.pesti.jp/yumevision2020/.
} 
Cormick, C. (2012). 'How do we gain the interest of people who are uninterested in science and technology?' In: Little by little expansion of nanoscience and emerging technologies. Ed. by H. Van Lente, C. Coenen, T. Fleischer, K. Konrad, L. Krabbenborg, C. Milburn, F. Thoreau and T. Zülsdorf. Amsterdam, The Netherlands: IOS Press, pp. 77-88.

Cormick, C. and Romanach, L. M. (2014). 'Segmentation studies provide insights to better understanding attitudes towards science and technology'. Trends in Biotechnology 32 (3), pp. 114-116. https://doi.org/10.1016/j.tibtech.2013.12.005.

Council for Science, Technology and Innovation (2017). Comprehensive strategy on science, technology and innovation for 2017 (excerpt).

URL: http://www8.cao.go.jp/cstp/english/doc/2017stistrategy_main.pdf (visited on 21st June 2018).

Delgado, A., Kjølberg, K. L. and Wickson, F. (2011). 'Public engagement coming of age: from theory to practice in STS encounters with nanotechnology'. Public Understanding of Science 20 (6), pp. 826-845. https://doi.org/10.1177/0963662510363054.

Department of Energy and Climate Change (2012). Evaluation of the process and outputs of the Low Carbon Communities Challenge (LCCC). URL: https://www gov .uk/government/uploads/system/uploads/attachment_data/file/48459/579 0 -opm-evaluation-of-the-process-and-outputs-of-the-l.pdf (visited on 21st June 2018).

Floud, R., Fuchs, Z. M., R., C. and Hynes, M. (2013). Science in society: caring for our futures in turbulent times. URL: http://archives.esf .org/fileadmin/Public_d ocuments/Publications/spb50_ScienceInSociety.pdf (visited on 21st June 2018).

Goto, T., Kudo, M. and Kano, K. (2015). 'Measuring representativeness of participants in public engagement events'. Japanese Journal of Science Communication 17 (07), pp. 3-19. URL: http://hdl . handle.net/2115/59575.

Goto, T., Mizumachi, E., Kudo, M. and Kano, K. (2014). 'Verification on the utility of using the segmentation method developed in Australia to assess audiences of science and technology events'. Japanese Journal of Science Communication 15 (06), pp. 17-35. URL: http://hdl . handle.net/2115/56441.

Kano, K., Mizumachi, E., Iwasaki, T., Isobe, H., Kawahito, Y. and Maenami, H. (2013). 'Segmentation and targeting of participants in science cafes: from the viewpoint of the extent of engagement in science and technology'. Japanese Journal of Science Communication 13, pp. 3-16. https://doi.org/10.14943/61989.

Kano, K. (2014). 'Toward achieving broad public engagement with science, technology and innovation policies: trials in JAPAN Vision 2020'. International Journal of Deliberative Mechanisms in Science 3 (1), pp. 1-23. https://doi.org/10.4471/demesci.2014.12.

Kotler, P. and Lee, N. R. (2007). Social marketing: influencing behaviors for good. 3rd ed. U.K.: SAGE.

Lijphart, A. (1997). ‘Unequal participation: democracy's unresolved dilemma presidential address, american political science association, 1996'. American Political Science Review 91 (01), pp. 1-14. https://doi .org/10.2307/2952255.

Lowndes, V., Pratchett, L. and Stoker, G. (2001). 'Trends in public participation: part 2 - citizens' perspectives'. Public Administration 79 (2), pp. 445-455. https://doi.org/10.1111/1467-9299.00264. 
Ministry of Education, Culture, Sports, Science and Technology (1993). White paper on science and technology 1993. Japan.

- (2014). Japan vision 2020. Japan.

URL: http://www.mext.go.jp/en/news/topics/detail/1372653.htm (visited on 21st June 2018).

Mohr, A., Raman, S. and Gibbs, B. (2014). Which publics? When? Exploring the policy potential of involving different publics in dialogue around science and technology. URL: http://eprints . nottingham.ac.uk/2896/1/Which-publics-FINAL-VERS ION . pdf (visited on 21st June 2018).

National Institute of Science and Technology Policy, Ministry of Education, Culture, Sports, Science and Technology (2018). Analytical report for NISTEP expert survey on japanese SET and innovation system 2017 (NISTEP TEITEN survey 2017). URL: http://data.nistep.go.jp/dspace/bitstream/11035/3195/348/N ISTEP-NR175-FullJ . pdf (visited on 21st June 2018).

Newman, J., Barnes, M., Sullivan, H. and Knops, A. (2004). 'Public participation and collaborative governance'. Journal of Social Policy 33 (02), pp. 203-223. https://doi.org/10.1017/s0047279403007499.

Organisation for Economic Co-operation and Development (2014). Science, technology and industry outlook. URL: http://www.oecd.org/sti/oecd-scien ce-technology-and-industry-outlook-19991428.htm (visited on 21st June 2018).

- (2016). PISA results from PISA 2015, country note: Japan. URL: http: //www. oecd.org/pisa/pisa-2015-Japan. pdf (visited on 21st June 2018).

Scupin, R. (1997). 'The KJ method: a technique for analyzing data derived from japanese ethnology'. Human Organization 56 (2), pp. 233-237. https://doi.org/10.17730/humo.56.2.x335923511444655.

Smith, G. (2009). Democratic innovations: designing institutions for citizen participation. Cambridge, U.K.: Cambridge University Press.

Smith, G. and Stephenson, S. (2005). 'The theory and practice of group representation: reflections on the governance of race equality in Birmingham'. Public Administration 83 (2), pp. 323-343. https://doi.org/10.1111/j.0033-3298.2005.00452.x.

Stilgoe, J. and Burall, S. (2013). 'Windows or doors? Experts, publics and open policy'. In: Future directions for scientific advice in Whitehall. Ed. by R. Doubleday and J. Wilsdon.

URL: http://www.csap.cam.ac.uk/media/uploads/files/1/fdsaw.pdf (visited on 21st June 2018).

Victorian Department of Innovation, Industry and Regional Development (2011). Community interest and engagement with science in Victoria. URL: http://science. sweeneyresearch.com.au/ (visited on 21st June 2018).

Kei Kano, $\mathrm{PhD}$, is an associate professor at the Science Communication Laboratory, Graduate School of Education, Shiga University, Japan. He has worked widely in science communication or public engagement for grade school students, adults, and early-career scientists. Dr. Kano is interested in inclusiveness of science communication or public engagement activities. E-mail: kkano@edu.shiga-u.ac.jp. 
Mitsuru Kudo, $\mathrm{PhD}$, is an associate professor at the Center for the Study of Co* Design, Osaka University. Over the last ten years he has been working on several research projects on various topics in and around science communication, including science literacy, public participation, community engagement and science communication policy. He also teaches science communication in the Programme for Education and Research on Science and Technology in Public Sphere, a postgraduate minor programme delivered at the Osaka University. E-mail:mkudo@cscd.osaka-u.ac.jp.

Go Yoshizawa, PhD is Research Fellow at Work Research Institute (AFI), OsloMet - Oslo Metropolitan University. Designing, organising and facilitating dozens of transdisciplinary projects, meetings and workshops, he has committed himself to future-oriented strategic intelligence in science and technology policy including technology assessment, foresight and responsible research and innovation. His current research interests include knowledge policy and management, intermediary organisations, and non-verbal communication for wider engagement in science and innovation. E-mail: gyosh@oslomet.no.

Eri Mizumachi, $\mathrm{PhD}$, is a specially appointed assistant professor at the Center for the Study of Co* Design, Osaka University, Japan. She received her Dr. of Agriculture degree from Kyoto University in 2008. She is interested in the interaction between scientists and public. She has coordinated several science cafes and developed educational programs for $\mathrm{K}-12$ students.

E-mail: mizumachi@cscd.osaka-u.ac.jp.

Makiko Suga is a Professor of Economics and Business Management Department of Tezukayama University. She also is a Visiting researcher of Graduate School of Public Health Kyoto University. Her research interests are health care management and marketing, especially from the viewpoint of the people. Recently she is interested in the relationship between the management of the companies and healthcare conditions of the companies' employee.

E-mail: suga@tezukayama-u.ac.jp.

Naonori Akiya is lecturer in the Faculty of Global and Science Studies, Yamaguchi university, Japan. He recieved his Dr. of Philosophy from Saitama University, Japan in 2009. His major is sociology, especially ethnomethodology and conversation analysis. His research involves the detailed analysis of work and interaction, drawing upon video-recordings of everyday human conduct.

E-mail: akiya@yamaguchi-u.ac.jp.

Kuniyoshi Ebina is a professor emeritus of Kobe University and a visiting professor of Open University of Japan. He got his Ph.D. in engineering from Osaka University, Japan in 1982. His major is theoretical physics on condensed matter, chemical and biological systems, and environmental science. He is engaging a science education program for high school students. E-mail: ebina@kobe-u.ac.jp.

Takayuki Goto is an assistant professor at the School of Human Cultures, The University of Shiga Prefecture, Japan. He received his Ph.D. in education from Kyoto University, Japan in 2015. His research interests include how children learn and are motivated to learn the knowledge of science. E-mail: goto.t@shc.usp.ac.jp. 
Masayuki Itoh is a researcher at the Graduate School of Human Development and Environment, Kobe University, Japan. He received his Ph.D. in Physics from the University of Tokyo in 1988. His major is Astrophysics. His current research interest is in radon gas emanation on the lunar surface in the field of astrophysics. He leads a project to develop a model of a system to support citizen's scientific activities in a local community in Japan. E-mail: itoh@radix.h.kobe-u.ac.jp.

Ayami Joh is a postdoctoral fellow at the University of Shiga Prefecture, Japan. She received her Ph.D. in human cultures from the University of Shiga Prefecture in 2013, and worked at the National Institute of Informatics, Kyoto University, and Shiga University. She has conducted conversation analytic research on the organization of interactions in ordinary and institutional settings, and focused on the organization of embodied practices for implementing social actions. Her current research interests include sightseeing, science communication, and elderly care. E-mail: subliminal_moving_in_aj@yahoo.co.jp.

Haruhiko Maenami is an Associate Professor at the Platform for Community -based Research and Education, Tottori University, Japan. He received his Doctor of Philosophy from Tohoku University, Japan in 2013. His major is sociology for science, especially knowledge transfer between Academia-Industry. Recently he has interest in communication methods for promoting cooperative works to define social situations and problems. E-mail: ha19000.com@gmail.com.

Toshifumi Minamoto is an associate professor at the Graduate School of Human Development and Environment, Kobe University, Japan. He got his Ph.D. in science from Kyoto University, Japan in 2003. His major is ecology of aquatic animals, especially fish and amphibians. Recently, he develops environmental DNA analysis methods for assessing aquatic biodiversity and uses these methods as tools for citizen sciences. E-mail: minamoto@people.kobe-u.ac.jp.

Mikihiko Mori is an Associate Professor of Research Center for Computing and Multimedia Studies at Hosei University, Japan. He received his Ph.D. in Engineering from Tokyo Institute of Technology, Japan. His current research interest focuses on what information aids assessing computer-supported collaborative learning. He has published several papers on computer systems with cooperative/collaborative user interfaces in educational environments. E-mail: mikihiko.mori.64@mori.grhosei.ac.jp.

Yoshitaka Morimura is a program-specific associate professor in Center for the Promotion of Excellence in Higher Education, Kyoto University, Japan. He received his Ph.D. in informatics from Kyoto University in 2012. His major is computer science, especially media computing for social application. His current research interest is in analysis and visualization of social big data.

E-mail: morimura.yoshitaka.f45@kyoto-u.jp. 
Tamaki Motoki, PhD is an assistant professor at Institute for Information Management and Communication, Kyoto University, Japan. She has been collaborative working with researchers to design and crate for academic contents at University. She studied visual design for academic activities and received her Ph.D in Fine Arts. Her recent research topics are Content design process and communication in non-profit activities, construction of sustainable model of first-person design, and record and description of design activities.

E-mail: motoki.tamaki.3c@kyoto-u.ac.jp.

Akie Nakayama is an Academic Researcher at Kobe University, Japan. She recieved her Ph.D. in Science from Kyoto University, Japan. Her major is Molecular and Developmental Biology. Her current research interests are science education and science communication. E-mail: nakayam@tiger.kobe-u.ac.jp.

Katsuya Takanashi is a researcher in Graduate School of Informatics, Kyoto University, Japan. He received his Ph.D. in informatics from Kyoto University in 2014. His major is communication science, especially applied conversation analysis. His current research interest is in conversation analysis in socially and cognitively complex human environment. E-mail: takanasi@sap.ist.i.kyoto-u.ac.jp.

\section{How to cite}

Kano, K., Kudo, M., Yoshizawa, G., Mizumachi, E., Suga, M., Akiya, N., Ebina, K., Goto, T., Itoh, M., Joh, A., Maenami, H., Minamoto, T., Mori, M., Morimura, Y., Motoki, T., Nakayama, A. and Takanashi, T. (2019). 'How science, technology and innovation can be placed in broader visions - Public opinions from inclusive public engagement activities'. JCOM 18 (03), A02.

https://doi.org/10.22323/2.18030202. 